Research Article

\title{
Study on the Calculation Method of the Diffusion Range of Grouting Slurry for a High-speed Railway Ballastless Track Subgrade
}

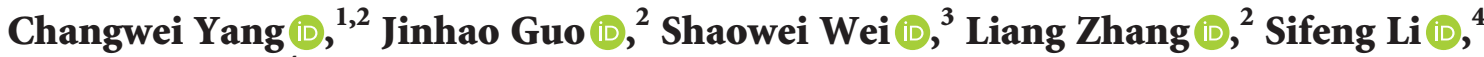 \\ and Yang Liu $\mathbb{1}^{4}$ \\ ${ }^{1}$ State Key Laboratory of Geohazard Prevention and Geoenvironment Protection (China), Chengdu 610059, China \\ ${ }^{2}$ Dept. of Civil Engineering, Southwest Jiaotong University, Chengdu 610031, China \\ ${ }^{3}$ Railway Engineering Research Institute, China Academy of Railway Sciences, Beijing 100044, China \\ ${ }^{4}$ Zhongke(Hunan) Advanced Rail Transit Research Institute, Zhuzhou 412000, China
}

Correspondence should be addressed to Shaowei Wei; wsw_cars@126.com

Received 28 January 2020; Revised 13 March 2020; Accepted 23 October 2020; Published 6 January 2021

Academic Editor: Peixin Shi

Copyright (C) 2021 Changwei Yang et al. This is an open access article distributed under the Creative Commons Attribution License, which permits unrestricted use, distribution, and reproduction in any medium, provided the original work is properly cited.

\begin{abstract}
Grouting engineering is the most convenient and quick way to deal with postconstruction settlement. Based on the investigation of the Beijing Shenyang high-speed railway in the early stage, the microdestructive force of grout on the soil mass in the process of grouting with the method of fluid solid coupling theory was analyzed. The numerical simulation results show that, in the grouting process, the greater the grouting pressure, the wider the diffusion range of the slurry and the greater the damage to the microscopic contact force of the slurry to the soil; in addition, when the grouting pressure is below $0.15 \mathrm{MPa}$, the diffusion form of the slurry in the soil is osmotic grouting; when the pressure is about $0.3 \mathrm{MPa}$, the diffusion form of the slurry in the soil is compacted grouting; on the basis of the simulation results, a deeper research is carried out, and the calculation formula of the slurry diffusion curve is obtained. It fills in the blank of the theoretical study of the slurry diffusion curve. In this paper, the diffusion formula of grouting slurry can be used in the theoretical study of clay grouting, and it can be used as a reference for practical engineering.
\end{abstract}

\section{Introduction}

In the recent years, the development of high-speed railway in China has been very rapid. With the development and improvement of the railway system, the problems exposed in the railway operation stage have also been valued by researchers. In the operational stage, high-speed railways will have different levels of subgrade settlement problems due to the different soil properties in different places. As a kind of roadbed settlement treatment method with convenient operation and excellent antisinking effect, grouting engineering has been widely used in the world. However, the research of grouting engineering by domestic and foreign researchers is far behind engineering practice. This is because the concealment of grouting engineering and the complexity of soil properties have caused researchers to study grouting engineering difficulties.

Many researchers have carried out different research studies on the microscopic mechanism of grouting engineering and the macroscopic antisinking effect and have obtained valuable research theories and experience in grouting [1-3]. Ho et al. used the finite element software Abaqus to study the mechanical properties of grouting materials under different confining pressures [4]; Rahimi et al. used neural network algorithms to study the waterproofing and penetrating function of the Bakhtiari dam [5]; Moayed et al. measured the shear strength of grouted stone bodies based on the laboratory test [6]; Zhu et al. used experiments to analyze the grouting reinforcement effect of 
different grouting materials [7]; Li et al. used the multiphysics coupling analysis finite element calculation software Comsol Multiphysics to study the influence of grouting on surface subsidence and groundwater seepage field during foundation pit excavation [8]. Li et al. focused on an improved prediction model to determine the limiting grouting pressure of compaction grouting considering the ground surface upheaval, which is caused by the three-dimensional conical shearing failure.

In summary, due to the limitations of current computing resources and the lack of experimental conditions, most of researchers only conduct research on a certain convenience of grouting engineering. In response to this research phenomenon, the research team carried out a series of research methods on the site inspection, laboratory test, numerical simulation, and field test of the typical section from the railway roadbed grouting project. Based on the work that the research team has carried out, this paper combines the study of the microscopic grouting mechanism with the calculation method of slurry diffusion and deeply studies the interaction between slurry and soil during grouting.

\section{Fundamental}

2.1. Discrete Element Contact Model. The simulation can simulate the interaction between particles and fluid accurately EDEM-FLUENT coupling, not only considering the force of the fluid on the particles but also the resistance of the particles to the fluid. The two-way coupling of two software in grouting research has its own unique advantages.

Firstly, the soil contact model to study the damage of the mesocontact force of grouting is selected. EDEM provides a variety of particle contact models for selection, such as the Hertz-Mindlin contact model, Hertz-Mindlin bond model, and Hertz-Mindlin heat transfer. In this paper, the HertzMindlin bonding model (Hertz-Mindlin with bonding model) was used to simulate the soil.

The contact force and moment in the model can be decomposed into normal vectors $\left(F^{n}, M^{n}\right)$ and tangential vector $\left(F^{s}, M^{S}\right)$. In the parallel bond model, normal stiffness $\left(\mathrm{N} \cdot \mathrm{m}^{3}\right)$ and tangential stiffness $\left(\mathrm{N} \cdot \mathrm{m}^{3}\right)$ are $\left(k^{n}, k^{s}\right)$ and normal tensile strength $\left(\mathrm{N} \cdot \mathrm{m}^{-2}\right)$ and tangential shear strength $\left(\mathrm{N} \cdot \mathrm{m}^{-2}\right)$ are $\left(\bar{\sigma}_{c}, \bar{\tau}_{c}\right)$. The radius of the bonding area is $R$.

Within one time step, the contact normal and tangential increments resulting from the contact displacement increment are

$$
\begin{aligned}
& \Delta F^{n}=-k^{n} A \Delta u^{n}, \\
& \Delta F^{s}=-k^{s} A \Delta u^{s},
\end{aligned}
$$

where $\left(A=\pi R^{2}\right)$ is the equivalent disc area, $\Delta u^{n}$ is the normal direction of displacement, and $\Delta u^{s}$ is the tangential increment.

The normal and tangential increments of the contact torque generated by the incremental rotation are

$$
\begin{aligned}
& \Delta M^{n}=-k^{n} J \Delta \theta^{n}, \\
& \Delta M^{s}=-k^{s} J \Delta \theta^{s},
\end{aligned}
$$

where $J=(1 / 2) \pi R^{4}$ is the moment of inertia passing through the contact point for the equivalent disc cross section with the $\Delta \theta^{s}$ direction as the axis, and $\Delta \theta^{n}$ and $\Delta \theta^{s}$ are the direction of rotation increment and tangential increment, respectively.

According to the beam theory of material mechanics, the formula for calculating the maximum tensile stress and shear stress acting on the equivalent disk is

$$
\begin{gathered}
\sigma_{\text {max }}=\frac{\left|F^{n}\right|}{A}+\frac{\left|M^{S}\right|}{I} R, \\
\tau_{\text {max }}=\frac{\left|F^{S}\right|}{A}+\frac{\left|M^{n}\right|}{I} R .
\end{gathered}
$$

$\bar{\sigma}_{\max } \geq \bar{\sigma}$ or $\bar{\tau}_{\max } \geq \bar{\tau}$, bonding damage. $R$ is the contact radius of the particle, which is set to $3.5 \mathrm{~mm}$ in this manuscript.

In EDEM, the particle cohesion between particles by a critical normal stress, the tangential shear bond strength, and bonded disk radius between the particles are determined. If the bond strength between the particles reaches or exceeds this critical value during the simulation, the contact bond will be destroyed.

2.2. Fluid-Particle Interaction Force. In CFD-DEM coupling algorithm, there are some mechanical models used to calculate the particle-fluid interaction force, such as the Drag Model, Lift Model, and Interfacial Heat Transfer Models $[9,10]$. At the same time, this manuscript focuses on the soil particle-slurry interaction forces which are mainly drag force. Therefore, the Di Felice drag model [11] is selected to calculate the particle-fluid interaction force, and it can consider the interaction among particles by introducing volume fractions of single particle, which is used in other similar studies $[12,13]$. The Di Felice drag model is shown as follows:

$$
\begin{aligned}
F_{d} & =\frac{\pi\left(d_{p}\right)^{2}}{2} C_{D} \rho_{f}\left|v_{f}-v_{s}\right|\left(v_{f}-v_{s}\right) \varepsilon_{s}^{-(\chi+1)}, \\
\chi & =3.7-0.65 \exp \left[-\frac{\left(1.5-\log 10 \mathrm{Re}_{s}\right)^{2}}{2}\right], \\
C_{D} & =\left(0.63+4.8 \sqrt{\mathrm{Re}_{s}}\right)^{2} .
\end{aligned}
$$

In the abovementioned formulas, $d_{p}$ is the particle diameter, $C_{D}$ is the drag coefficient of single particle, $\rho_{f}$ is the fluid phase density, $\varepsilon_{s}$ is the volume fraction of the particle phase, $v_{f}$ is the fluid phase velocity at the particle center, $v_{s}$ is the particle phase velocity, $\operatorname{Re}_{s}$ is the particle Reynolds number. 


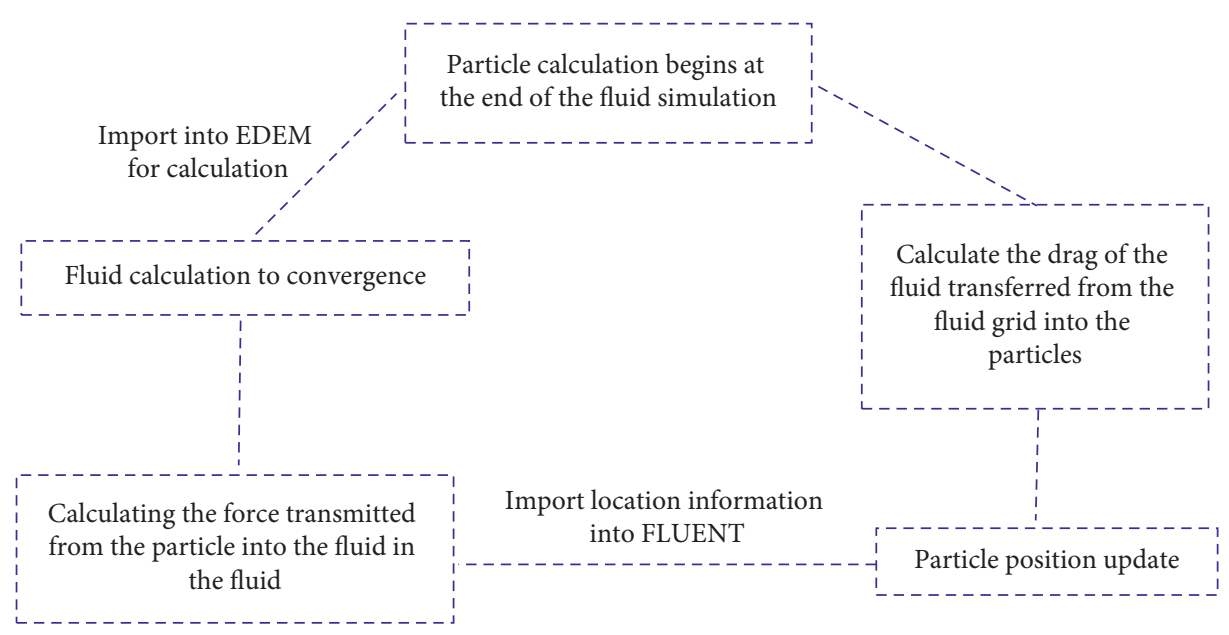

Figure 1: Coupled simulation flow chart.

\section{Discrete Element Contact Model}

In this microlevel, CFD-DEM coupling algorithm is used to simulate the whole grouting process. FLUENT is a popular computational fluid dynamics simulation software in the world, and EDEM can be widely used in many scientific research fields, such as mining, geotechnical, agriculture, and so on. The seamless coupling between fluent-EDEM and FLUENT-EDEM is also the world's leading CFD-DEM coupling calculation method. The coupling flow between the two software is shown in Figure 1.

\section{Grouting Microscopic Mechanism Research Model}

4.1. Calculation Model. In EDEM, there are many soil particle models, in this paper, we used the Hertz-Mindlin bonding model to simulate soil. Due to the limitation of subgrade size and computer resources, it is impossible to simulate the soil with real graded soil particles in EDEM. Therefore, in this simulation, the spherical particles were simulated with spherical particles with a particle size of $6 \mathrm{~mm}$, and a simplified model of $60 \mathrm{~cm} \times 60 \mathrm{~cm} \times 30 \mathrm{~cm}$ was used to simulate the subgrade structure. As shown in Figure 2, 599044 spherical particles were filled.

4.2. Parameter Settings. In the calculation process, due to the excessive size of the subgrade structure in this simulation, it is necessary to consider the surrounding rock pressure in the subgrade soil, so the micromechanical parameters are corrected in the simplified model of the subgrade [14]. The particle simulation parameters are shown in Table 1, and the slurry parameters in fluent are shown in Table 2.

\section{Results Analysis}

5.1. Microscopic Grouting Mechanism Analysis. The grouting is a complex physical process, and its principle is to form stone body by the diffusion of grouting slurry in the roadbed, so as to enhance the bearing capacity of soil and achieve the

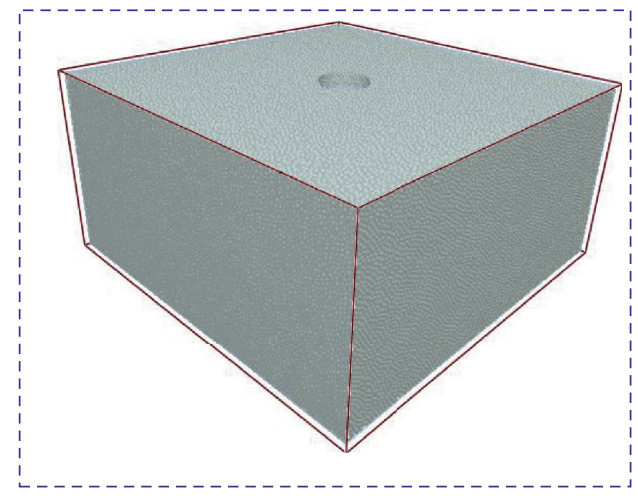

Figure 2: Model after particle filling.

TABLE 1: Particle simulation parameters.

\begin{tabular}{lc}
\hline Particle diameter $(\mathrm{mm})$ & 6 \\
Static friction coefficient & 0.4 \\
Density $\left(\mathrm{kg} / \mathrm{m}^{3}\right)$ & 1920 \\
Poisson's ratio & 0.28 \\
Gravity acceleration $\left(\mathrm{m} / \mathrm{s}^{2}\right)$ & 9.81 \\
Parallel bond stiffness $\left(\mathrm{N} / \mathrm{m}^{3}\right)$ & $1.50 E+06$ \\
Normal bond stiffness $\left(\mathrm{N} / \mathrm{m}^{3}\right)$ & $1.50 E+06$ \\
Normal critical stress $(\mathrm{Pa})$ & $2.00 E+08$ \\
Tangential critical stress $(\mathrm{Pa})$ & $2.00 E+08$ \\
\hline
\end{tabular}

TABLE 2: Slurry parameters in fluent.

Density $\left(\mathrm{kg} / \mathrm{m}^{3}\right)$ Cement viscosity Specific heat capacity $(\mathrm{J} / \mathrm{kg} \cdot \mathrm{K})$ \begin{tabular}{lll}
\hline 1760 & 0.06 & 840
\end{tabular}

purpose of settlement control. It can be seen from Figure 3 that when the pressure is small, the movement of the slurry in the soil is in the form of infiltration; when the pressure is high, the slurry appears as compacted grouting in the soil; when the grouting pressure continues to increase, the mode of action of the slurry on the soil is cleft. With the increase of the calculated pressure, the damage degree of the slurry to the soil is also increasing. Figure 4 is an overview of the scope of the extrusion area. Each circle represents the scope of the 


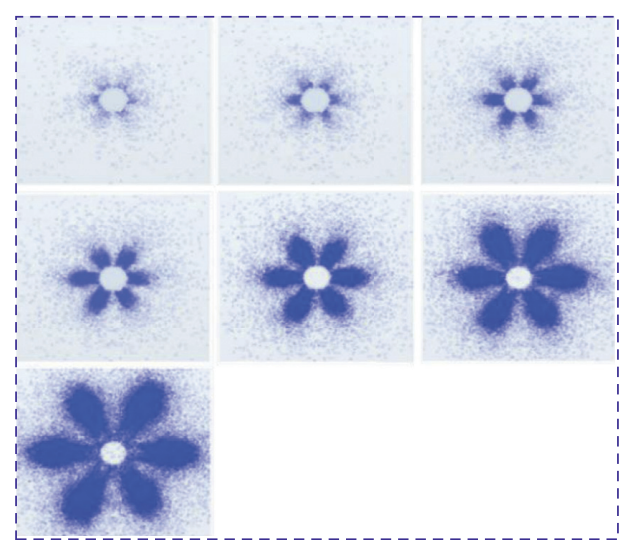

FIgURE 3: Influence range chart under each grouting.

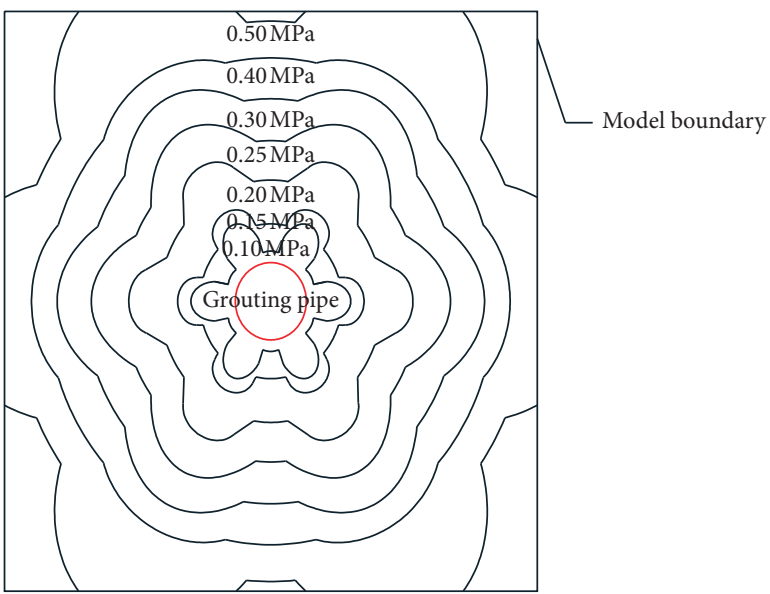

FIGURE 4: Extrusion zone range map for each grouting.

extrusion area under different grouting pressure. Figure 4 clearly depicts the regular increase of extrusion area with the increase of pressure. At $0.5 \mathrm{MPa}$, the extruded area reaches $32.8 \mathrm{~cm}$, and the range of each extruded area is shown in Figure 5.

Comprehensive analysis can be seen in Figures 3-5; the range of splitting increases with the increase of grouting pressure, and the slope of its curve is also increasing which means that the radius changes faster and faster, probably because that the slurry destroyed the soil structure when the grouting pressure was too high. Also, it is observed from Figure 5 that, during the grouting process, the influence of the slurry on the soil appears as an impact shape and is symmetrically distributed in the radial direction of the six grouting holes. Moreover, when the grouting pressure is low, the shape is not obvious, the reason of which is that the effect of the slurry on the soil is small while the pressure is low. At the same time, when the grouting pressure is large, the effect of the slurry on the soil becomes larger, and the response to the slurry on the microscopic level of the soil is also gradually increased. Figure 5 is fitted to the curve to obtain the mathematical curve of the splitting radius and grouting pressure as $R=64.53 p^{1.331}$, and the fitting degree reaches 0.9755 ,

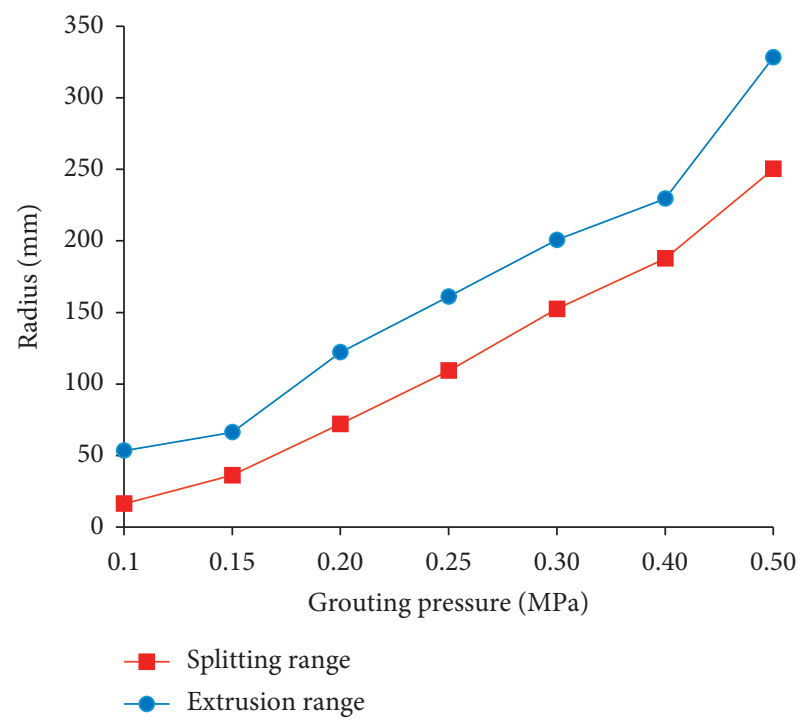

FIGURE 5: Grouting splitting range and extrusion zone range change.

which is a power exponential relationship between the splitting radius and the grouting pressure.

5.2. Slurry Diffusion Range Calculation Method. From the abovementioned range of influence of the slurry on the soil, a very regular change can be obtained. Due to the limitation of space, this paper selects the contact failure map of the soil at the microscopic level of $0.4 \mathrm{MPa}$ for analysis. The contact key damage envelope diagrams of the change graph are described, as shown in Figure 6.

Then, we take the center of the grouting pipe as the coordinate origin and take the upper part of the curve for analysis and observed that the envelope diagram can be divided into two parts: the first half is a logarithmic curve, and the second half is part of a circle. We select 20 coordinate points in the first half of the curve to export the coordinate points to the EXCEL for processing and obtain the coordinate curve as shown in Figure 7. In Figure 7, the curve can be divided into two parts with the point (X2, Y2) as the boundary.

Fitting the curve of the first half of the curve in Figure 7 is as shown in Figure 8. We got the first half of the curve equation as $y=2.2348 \ln x-1.3719$, whose fitting degree reached 0.9803 .

The second half is like a circle and is fitted with a circular equation. We import the graphic into AUTOCAD and measure the radius of the circle to be $4.36 \mathrm{~cm}$ and the coordinates of the center of the circle to be $16.50 \mathrm{~cm}$. So, the standard equation for the envelope curve of the second half is $\left((x-16.5)^{2}+y^{2}=4.36^{2}\right)$, and through the statistical analysis of the envelope curve, the ratio of the diffusion radius $R_{1}$ of the first half to the diffusion radius $R_{2}$ of the second half is about $3: 1$.

It can be observed from Figure 4 that the envelope curve of the damage range only increases as the pressure increases, but its shape does not change. Unknown constants in the expression are set as $a, c, d$, and $r$, so it can be assumed that 


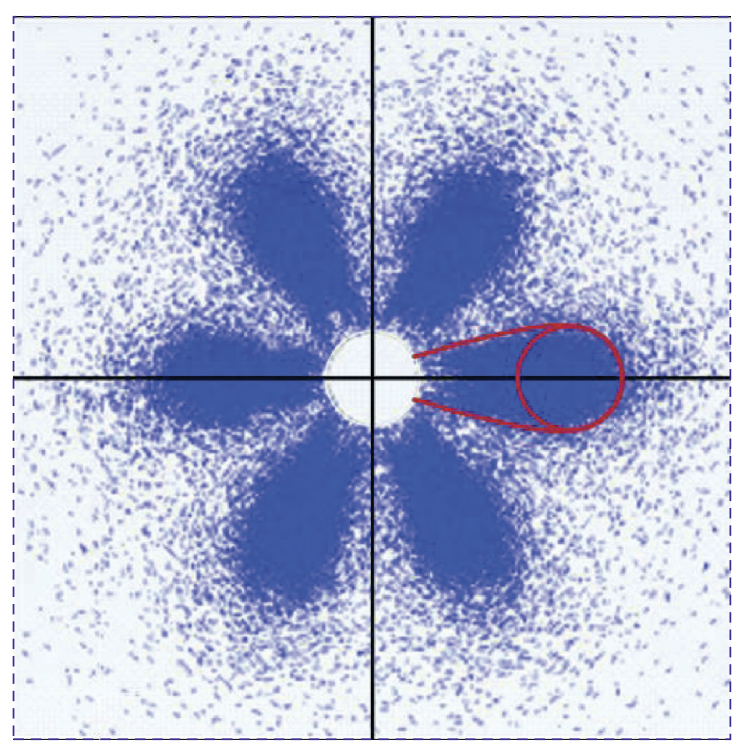

Figure 6: Soil contact bond failure range diagram at $p=0.4 \mathrm{MPa}$.

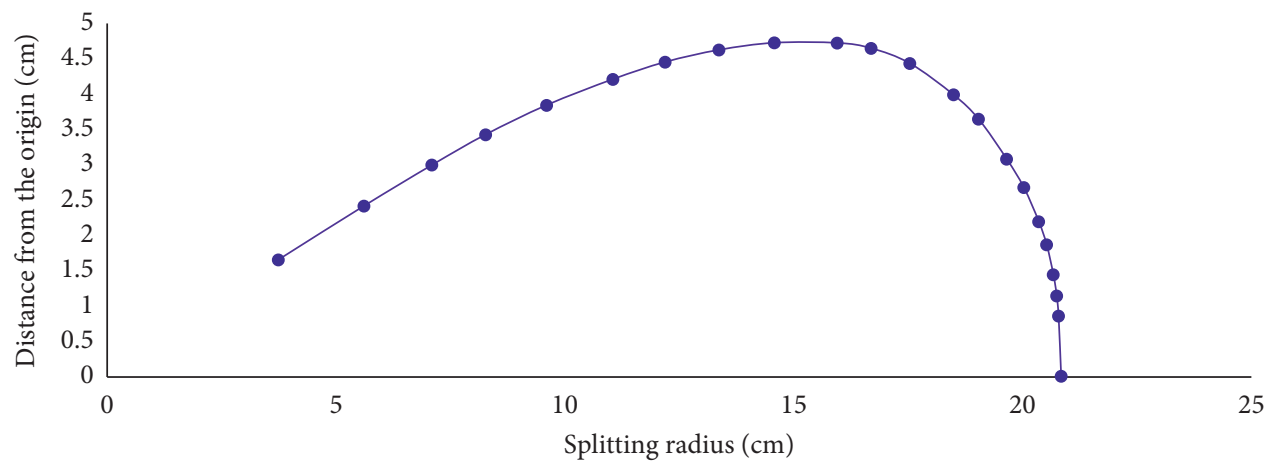

FIgURe 7: Contact bond damage range envelope curve.

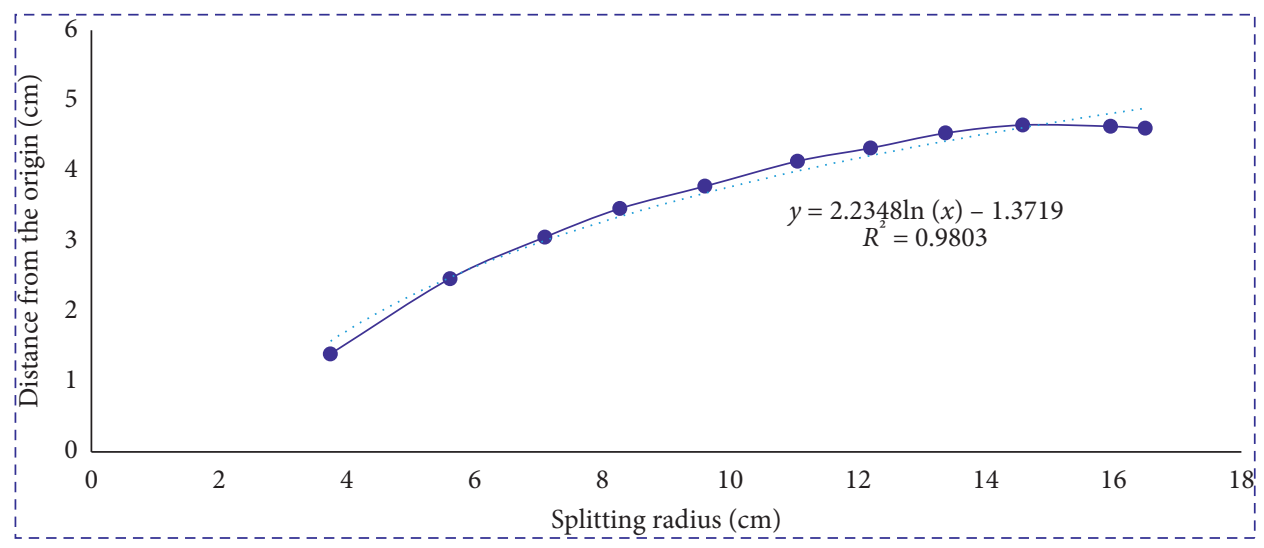

Figure 8: The first half of the curve of the envelope curve. 
the mathematical curve expression of the contact failure of the soil contact bond under different grouting pressure is $\left\{\begin{array}{l}y=a \ln x+c \\ (y-d)^{2}+x^{2}=r^{2}, x>0, y>0, \text { and the unknown coeffi- }\end{array}\right.$ cients are $a, c, d$, and $r$. Therefore, the assumption is made that the unknown coefficients $a, c, d$, and $r$ are related to the pressure of grouting, and each grouting pressure corresponds to a set of coefficients, corresponding to a set of slurry diffusion curves. So, the next problem that we must solve is finding the relationship between $a, c, d, r$, and the grouting pressure $p$.

From Section 5.1, the relationship between grouting pressure and rupture radius is $R=64.53 p^{1.331}$, considering the radius of the grouting pipe and the origin of the coordinate at the center of the grouting pipe. So, the total radius $R$ of the slurry diffusion range mathematical expression is expressed as $R=64.53 p^{1.331}+b$, where $b$ is the radius of the grouting pipe.

In summary, the following equations can be obtained:

$$
\left\{\begin{array}{l}
R=64.53 p^{1.331}+b, \\
R=R_{1}+R_{2}, \\
y=a \ln x+c, \\
(x-d)^{2}+y^{2}=r^{2}, \\
R_{1}: R_{2}=3: 1 .
\end{array}\right.
$$

Among them, $R$ is the total length of the slurry diffusion radius, $R_{1}$ is the first half of the slurry diffusion radius, $R_{2}$ is the second half of the slurry diffusion radius, $b$ is the radius of the grouting pipe, $p$ is the grouting pressure, and $a, c, d$, and $r$ are the constants to be solved related to the grouting pressure.

As shown in Figure 9, we select two special points on the curve, select the connection point between the end point and the two-part connection curve, and set the coordinates to be $(x 1, y 1),(x 2, y 2)$

We bring $(x 1, y 1)$ and $(x 2, y 2)$ into mathematical equation (5). Since the curve in the graph is a continuous curve, the two parts of the curve are equal in the derivative of $(x 2, y 2)$, so the following equations are obtained:

$$
\left\{\begin{array}{l}
y_{1}=a \ln x_{1}+c, \\
y_{2}=a \ln x_{2}+c, \\
\left(x_{2}-d\right)^{2}+y_{2}^{2}=r^{2}, \\
(R-d)^{2}+0^{2}=r^{2}, \\
\left.y^{\prime}\right|_{x=x_{2}, y=y_{2}}=\frac{d-x_{2}}{y_{2}}=\frac{a}{x_{2}}, \\
\frac{x_{2}-b}{R-x_{2}}=\frac{3}{1}, \\
R=64.53 p^{1.331}+b .
\end{array}\right.
$$

In equation (6), we consider $x_{2}$ and $y_{2}$ as known constants and combine the first and second equations to solve $a$ and $c$ first and, then, combine the third equation with the fourth equation to solve for $c$ and $d$.

$$
\left\{\begin{array}{l}
a=\frac{y_{1}-y_{2}}{\ln x_{1}-\ln x_{2}}, \\
c=-\frac{y_{1} \ln x_{2}-y_{2} \ln x_{1}}{\ln x_{1}-\ln x_{2}}, \\
d=-\frac{-R^{2}+x_{2}^{2}+y_{2}^{2}}{2\left(R-x_{2}\right)}, \\
r=R-d=R+\frac{-R^{2}+x_{2}^{2}+y_{2}^{2}}{2\left(R-x_{2}\right)} .
\end{array}\right.
$$

In actual engineering, $x_{1}$ and $y_{1}$ can be directly derived, where $y_{1}$ is the radius of the shot hole on the grouting pipe, then $x_{1}$ can be calculated by the equation of the grouting pipe, and the calculation equation is $x^{2}+y^{2}=b^{2}$. In fact, $x_{2}$ and $y_{2}$ are unknowns. So, we can solve $x_{2}$ and $y_{2}$ by the following equations combined into a system of equations (8). Also, $x_{2}, y_{2}$ solved by it are shown in equation (9).

$$
\begin{aligned}
& \left\{\begin{array}{l}
\left.y^{\prime}\right|_{x=x_{2}, y=y_{2}}=\frac{d-x_{2}}{y_{2}}=\frac{a}{x_{2}}, \\
a=\frac{y_{1}-y_{2}}{\ln x_{1}-\ln x_{2}}, \\
d=-\frac{-R^{2}+x_{2}^{2}+y_{2}^{2}}{2\left(R-x_{2}\right)}, \\
\frac{x_{2}-b}{R-x_{2}}=\frac{3}{1},
\end{array}\right. \\
& \left\{\begin{array}{l}
x_{2}=\frac{3 R+b}{4}, \\
y_{2}=\frac{(R-b)\left(2 y_{1}+\sqrt{M}\right)}{N} .
\end{array}\right.
\end{aligned}
$$

In the equations,

$$
\begin{aligned}
& M=4 y_{1}^{2}+\frac{(R-b)(3 R+b)}{2}(B-A)+\frac{b^{2}}{4}(B-A)^{2}, \\
& N=2[2(R-b)+(3 R+b)(B-A)], \\
& A=\ln x_{1}, \\
& B=\ln \left(\frac{3 R+b}{4}\right) .
\end{aligned}
$$




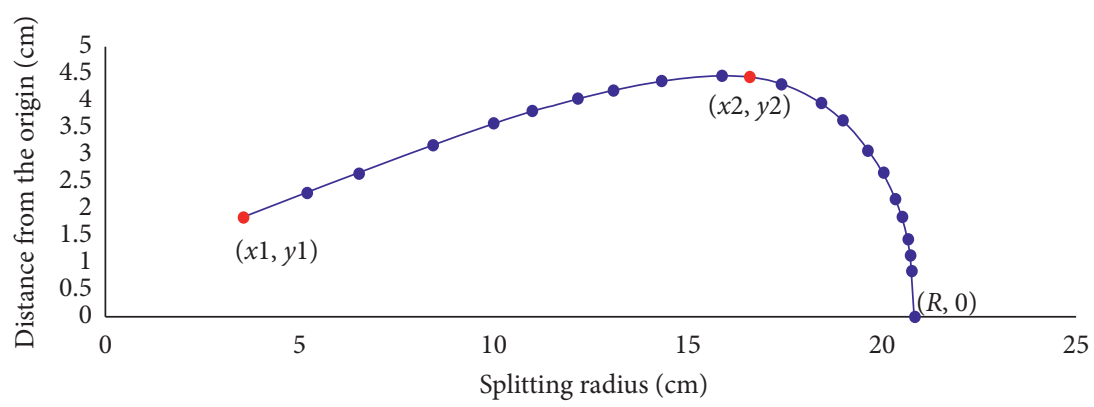

Figure 9: Point map on the curve.

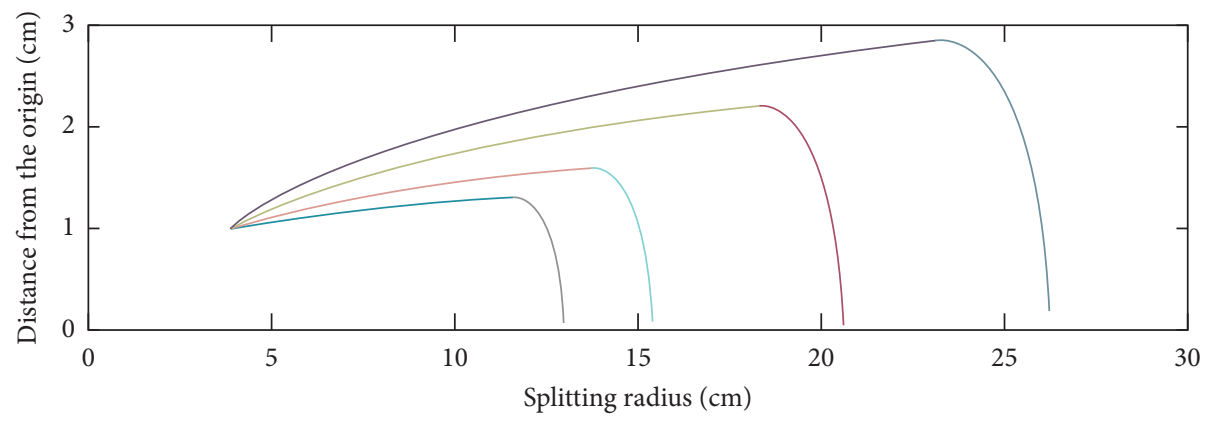

Figure 10: Calculated diffusion curve.

Therefore, a comprehensive analysis of all the abovementioned equations can be used to obtain the grouting diffusion curve equation as shown in the following equation:

$$
\left\{\begin{array}{l}
y=\frac{y_{1}-y_{2}}{\ln x_{1}-\ln x_{2}} \ln x-\frac{y_{1} \ln x_{2}-y_{2} \ln x_{1}}{\ln x_{1}-\ln x_{2}} \\
\left(R-\frac{-R^{2}+x_{2}^{2}+y_{2}^{2}}{2\left(R-x_{2}\right)}\right)^{2}+y^{2}=\left(\frac{R^{2}-2 R x_{2}+x_{2}^{2}+y_{2}^{2}}{2 R-2 x^{2}}\right)^{2},
\end{array} \quad x>0, y>0,\right.
$$

where $y_{1}$ is the radius of the shot hole, $x_{1}$ can be obtained by the equation $x^{2}+y^{2}=b^{2}$, and $x_{2}$ and $y_{2}$ are the coordinates of the joint of the two curves, which can be calculated by equation (9). $b$ is the radius of the grouting pipe. $R$ is the radius of the contact failure range of the microscopic layer of the soil, which can be calculated by the equation $R=64.53 p^{1.331}+b$. In this way, this paper obtained the mathematical expression of the grouting slurry diffusion curve under various grouting pressures.

\section{Parameters Research}

The relationship between grouting pressure and slurry diffusion has been obtained above. In order to confirm the applicability of the relationship, several pressures in the simulation are brought into the mathematical relationship to verify. This section takes $0.3 \mathrm{MPa}$ as an example to show the whole process of its calculation. First, $p=0.3 \mathrm{MPa}$ is brought into the equation $R=64.53 p^{1.331}+b$ to obtain the farthest damage range of the slurry at $0.3 \mathrm{MPa}$, which is $16.996 \mathrm{~cm}$. Then, we calculate the value of $x 2$, which is calculated as $x 2=(3 \mathrm{R}+b) / 4=13.747$ and, then, calculate the values of $M$ and $\mathrm{N}$ into 463.070 and 191.304, respectively. Finally, the value of $y 2$ can be calculated to be 1.598 . The values of $x_{1}, x_{2}$, $y_{1}$, and $y_{2}$ are, respectively, taken into the expression of the coefficient equation to obtain $a=0.472, c=0.361, d=14.979$, and $r=2.017$, respectively. So, when $p=0.3 \mathrm{MPa}$, the curve expression of the slurry diffusion range is

$$
\left\{\begin{array}{l}
y=0.472 \ln x+0.361, \\
(x-14.979)^{2}+y^{2}=2.017^{2},
\end{array} \quad x>0, y>0 .\right.
$$

The slurry diffusion curves at other grouting pressures are simultaneously plotted in one figure, as shown in Figure 10. The expected result is basically consistent with the results obtained in the simulation. The slurry diffusion curves under other grouting pressures are simultaneously 
plotted in a graph, as shown in Figure 10. It can be seen that the diffusion curve is basically consistent with the results obtained in the simulation.

\section{Conclusions}

This paper takes a high-speed rail grouting section in actual engineering as an example. After the previous site research work and after discussion by the research group, FLUENT and EDEM coupled simulation were used to analyze the microscopic force of subgrade grouting under microscopic analysis. The study analyzed the interaction between the slurry and the soil at the microscopic level and in-depth study of the calculation method of the diffusion range of slurry in soil. From the research work, this paper has the following conclusions:

(1) During the grouting process, the damage of the slurry to the soil is mainly related to the pressure of grouting. The extent of the damage of the slurry to the microscopic force of the soil increases with the increase of grouting pressure.

(2) In this simulation analysis test, when the grouting pressure is below $0.15 \mathrm{MPa}$, the diffusion form of the slurry in the soil appears as infiltration, and the influence on the soil surrounds about $3 \mathrm{~cm}$ around the grouting pipe; when the grouting pressure is about $0.3 \mathrm{MPa}$, the diffusion form of the slurry in the soil is compacted grouting, and the influence on the soil is about $15 \mathrm{~cm}$ around the grouting pipe; when the pressure of grouting exceeds $0.3 \mathrm{MPa}$, the damage of the slurry to the soil is in the form of splitting, which causes some damage to the structure of the soil.

(3) In the study of grouting engineering, the study of its calculation formula is an indispensable part. In this paper, through the calculation and analysis of the grouting microscopic process, the calculation formula of the diffusion envelope curve of the slurry is deduced, and the formula of the slurry diffusion curve is obtained, which lays a foundation for further theoretical research of the subsequent grouting project.

\section{Data Availability}

The data used to support the findings of this study are available from the corresponding author upon request.

\section{Conflicts of Interest}

The authors of this manuscript do not have any conflicts of interest regarding the publication of this article.

\section{Acknowledgments}

This study was supported in part by China Railway Eryuan Engineering Group Co., Ltd. Scientific Research Project (No. KYY2017069(17-17)); Sichuan Provincial Science and Technology Support Project (Nos. 2019JDRC0133 and 2019JDRC 0134); Science and Technology Research and
Development Plan of China National Railway Corporation Limited (N2019G022); and opening fund of State Key Laboratory of Geohazard Prevention and Geoenvironment Protection (Chengdu University of Technology) (No. SKLGP2015K019).

\section{References}

[1] M. Diagne, M. Codou Ndiaye, and S. Lèna, "Reinforcement of the ground by injection of cement grout for the installation of piles in karstified limestone zone," Case Studies in Construction Materials, vol. 12, 2020.

[2] X. Qi, C. he, T. Liu, and K. Wang, "Experimental study on the reinforcement of slope by secondary grouting steel tube micro pile," Geotechnical foundation, vol. 34, no. 1, pp. 12-16, 2020.

[3] S. Li, P. J. ZhangYang, Y. Chu et al., "Water-cement-density ratio law for the 28-day compressive strength prediction of cement-based materials," Advances in Materials Science and Engineering, vol. 2020, no. s1, pp. 1-8, 2020.

[4] D.-A. Ho, M. Bost, and J.-P. Rajot, "Numerical study of the bolt-grout interface for fully grouted rockbolt under different confining conditionsfferent confning conditions," International Journal of Rock Mechanics and Mining Sciences, vol. 119, no. 119, pp. 168-179, 2019.

[5] E. Rahimi, E. Sharifi Teshnizi, R. Ahmad, and E. Motamed Alshariati, "Cement take estimation using neural networks and statistical analysis in bakhtiari and karun 4 dam sites, in south west of Iran," Bulletin of Engineering Geology and the Environment, vol. 78, pp. 2817-2834, 2019.

[6] R. Z. Moayed, M. Hosseinali, S. M. ASCE, S. M. Shirkhorshidi, and J. Sheibani, "Experimental investigation and constitutive modeling of grout-sand interface," International Journal of Geomechanics, vol. 19, no. 5, pp. 1-13, 2019.

[7] M. Zhu, Q. Zhang, S. Li, L. I. Wei, H. Sui, and H. Yang, "Simulation test for main control factors of soil splitting grouting reinforcement," Journal of Zhejiang University (Engineering Science), vol. 52, no. 11, pp. 2058-2067, 2018.

[8] Z. Li, Y. Li, Li Zhang, and T. Song, "Numerical simulation study on grouting reinforcement effect of fault zone exposed in station foundation pi," Tunnel Construction, vol. 38, no. S2, pp. 111-119, 2018.

[9] N. G. Deen, M. V. S. Annaland, and M. A. V. D. Hoef, "Review of discrete particle modeling of fluidized beds," Chemical Engineering Science, vol. 62, no. 1-2, pp. 28-44, 2007.

[10] Z. Zhang, T. Yin, X. Huang, and D. Dias, "Slurry filtration process and filter cake formation during shield tunnelling: insight from coupled CFD-DEM simulations of slurry filtration column test," Tunnelling And Underground Space Technology, vol. 87, no. 5, pp. 64-77, 2019.

[11] R. D. Felice, "The voidage function for fluid-particle interaction systems," International Journal of Multiphase Flow, vol. 20, no. 1, pp. 153-159, 1994.

[12] P. D. Bonkinpillewar, A. Kulkarni, M. V. Panchagnula, and S. Vedantam, "A novel coupled fluid-particle DEM for simulating dense granular slurry dynamics," Granular Matter, vol. 17, no. 4, pp. 511-521, 2015.

[13] Z. Wang, Y. Teng, and M. Liu, "A semi-resolved CFD-DEM approach for particulate flows with kernel based approximation and Hilbert curve based searching strategy," Journal Of Computational Physics, vol. 384, no. 5, pp. 151-169, 2019.

[14] N. Yin, S. Li, Y. Shi, Z. Sun, and Z. Yin, "Discrete element analysis of the behavior of frozen loess cement under different confining pressures," Glacier, vol. 39, no. 4, pp. 858-867, 2017. 